production. To this end mechanization and more mechanization and more men to work the machine is the invariable answer. Is it quite certain that in some mines more coal-cutters and longer conveyorbelts are not indirectly diminishing output by the deleterious effects on the men ? It has almost become trite among doctors to say this is an engineering problem. Until the disease is controlled so as not to abridge life or seriously impair health in a normal working span, then the medical man must bear his full part in the team. But in this particular field the medical man is simply an expert adviser; he is not the director in charge of operations. Though the production of dust must be kept to a minimum, considerable dust is unavoidable, and the occurrence and, in certain circumstances, the progression of the disease reflects the extent of the dangerous concentrations of air-borne dust. The medical man has two main duties : first, to assist the engineers to locate the dangerous operations and stations, and secondly, to supervise the health of affected men still at work.

The final speaker, Sir Andrew Bryan (National Coal Board, London), speaking on "Accidents in Coal Mines", said that of all the major industries in Great Britain, coal-mining is the most hazardous. Employing less than one-twentieth of the working population, it accounts for nearly one-quarter of all industrial accidents. The reasons for this high accident-rate lie in the nature of the work of the miner and in the vital differences between his working environment and that of other industrial workers. Mining is for the most part a continual striving against great natural hazards in confined and poorly illuminated spaces.

Up to the present time the attack upon the accident problem has been mainly by statutory regulation and inspection, assisted by scientific research into specific mining dangers and a raising of the standards of education and training of miners; and, more directly, by improvements in standards of housing, welfare and recreational facilities for the mining community as a whole. That these lines of attack have achieved a considerable measure of success over the years is shown by the progressive reduction in the accidentrates for fatal and serious non-fatal accidents. There is still much to be done along these lines. The attack must continue by way of further regulations as the results of new mining methods, machines and safety practices are devised; by way of higher standards of education or training for mine managers, officials and workmen; by the general adoption of higher standards of engineering production; and by the expansion of social and welfare activities in all mining communities. But new methods are needed if the progress of accident reduction is to be accelerated ; and for this purpose new methods of investigation are required.

As examples of new lines of approach, the relationship between accident-rate, absenteeism and size of pit has been considered. There is a close correlation with the size of pit and the accident-rate per 100,000 man-shifts. In pits employing less than fifty miners the rate is $63 \cdot 5$, but rises to $166 \cdot 6$ in pits with more than three thousand. The reasons for this require study. Further, it can be shown that a high accidentrate can be correlated with a high pneumoconiosisrate. Researches into observable features of human behaviour such as accident-rates, and their relation to the size of the groups in which men work, may, in the final result, throw light upon the structure of authority in the pit and the extent to which the men feel themselves to be part of the organization in which they are employed. Coal must always be got by small groups of men working in isolation and under remote supervision. The attitudes of these groups and the extent to which they each identify themselves with the pit as a whole are problems needing urgent investigation that confront the industry.

\section{SENSES AND BEHAVIOUR OF ANIMALS}

$\mathrm{O}^{\mathrm{N}}$ August 13 at Edinburgh the second joint session of Sections D (Zoology) and J (Psychology) of the British Association (the first was at Aberdeen in 1934) was held under the chairmanship of Dr. C. F. A. Pantin, the subject being the "Senses and Behaviour of Animals".

Prof. R. J. Pumphrey (University of Liverpool) spoke of the coming of age of 'ethology', a word recently applied to the study of the behaviour of all animals including man. Ethology, in this wide sense, evidently stems from the "Origin of Species" (1859) and the "Expression of the Fmotions in Man and Animals" (1872); but its development has been arrested until very recently. This arrest is traceable to the influence of Descartes. In spite of the intellectual acceptance of evolution as a fact of history, a conscious or sub-conscious reservation in favour of dualism led to the persistent separation of a human ethology (psychology) which was rootless and arid, from an animal ethology, which carried the worship of the Golden Calf of objectivity to ludicrous lengths. The many 'languages of objective description' that have been applied to animal behaviour are seen in retrospect to cloak a belief in a physico-chemical etiology of behaviour, and an equation of meaning with statistical significance.

Prof. Pumphrey concluded that the time is now ripe for an integrated ethology with a common language and a common aim. A re-examination of the basic principles of semantics is needed, for semantics is doubly involved in ethology, both in the technique and in the description and interpretation of results.

The next speaker, Prof. J. E. Harris (University of Bristol), pointed out that a physiological and 'mechanistic' treatment is still appropriate to the genesis of behaviour patterns in the embryo. He showed in detail how this genesis can be related to the development of the muscular and nervous systems of young fish and amphibians, and how the first myogenic movements and rhythms are modified as motor and sensory nerve cells, and connexions and tracts become functional until the swimming rhythm is perfected.

Prof. R. W. Russell (University College, London) said that he was a psychologist and necessarily approached animal ethology with the terminology and point of view of human psychology. Nevertheless, he agreed with Prof. Pumphrey about the importance of semanties and the desirability of an integrated ethology with a common language. Such meetings as the present joint discussion and the Cambridge symposium on behaviour two years earlier reflect the desire of psychologists and animal ethologists alike to understand each other and to contribute jointly to an understanding of behaviour.

Prof. Russell then described the extensive field of animal psychopathology which has been explored 
since the first studies in experimental neurosis in Pavlov's laboratory at the beginning of the century ; and he convincingly demonstrated the close resemblance in the symptoms of neurotic behaviour of man and animals and in the situations which produce it. There is a fundamental difficulty in distinguishing 'normal' and 'abnormal' behaviour of animals in laboratory situations which are ex hypothesi abnormal. Nevertheless there is a promise, if not more than a promise, that animal and human psychopathology can be unified with significant results for our understanding of human behaviour.

In a review of learning by animals other than man, Dr. F. H. George (University of Bristol) emphasized the extent to which, after the earlier pioneering of Lloyd Morgan and Pavlov, the world was indebted to the United States for investigation in this field and for the elaboration of its somewhat indigestible theory. He emphasized in particular the unsatisfactory theoretical position of 'punishment', Muenziger et al. and Drew having shown that 'punishment' is as effective in reinforcing a right choice as in correcting a wrong one. He outlined the conflicting theories of learning of Tolman and Hull and seemed at least to hint that the conflict is partly verbal and terminological. Like previous speakers, Dr. George stressed the importance of a new semantic approach to ethological problems and suggested that a really comparative attitude is likely to be productive. In the 'comparative' psychology of recent years, 70 per cent of published papers deal only with the Norway rat.

In the subsequent discussion, Prof. H. R. Hewer neatly pointed Dr. George's concluding remarks, and criticized by implication the abstractness and remoteness from reality of much modern work on learning and behaviour. During the Second World War he had been concerned with others in countering the depredations of wild rats. Search of the enormous literature on the behaviour of rats in laboratories had disclosed little that was relevant or useful in the control of wild rats. It was not at that time even known how they ate.

\section{EFFECTS OF X-RAYS UPON PLASTICS}

\section{Electronic Processes}

$I^{\mathrm{N}}$ continuation of our work on systems suitable for the dosimetry of ionizing radiations, and in particular the measurement of three-dimensional dose distributions ${ }^{1}$, we have experimented with some coloured plastics. The observed phenomena, while indicating some applicability to the measurement of radiation, have aspects of more general interest.

It was found that of a series of thirty-two samples of commercially available polymethylmethacrylate ('Perspex'), coloured with various materials, three samples showed an appreciable change of colour when irradiated with X-rays. Similar results could be obtained using a plastic prepared by polymerization of an acrylic monomer coloured with benzeneazo-benzene-azo- $\beta$-naphthol (Sudan III). These colour changes are more intense than the slight colour changes shown by uncoloured 'Perspex', and of a different spectral composition. In addition, they are completely different from the slight bleaching caused in the same materials by ultra-violet light. The X-ray effect consisted in each case of the development of an absorption band at a wave-length

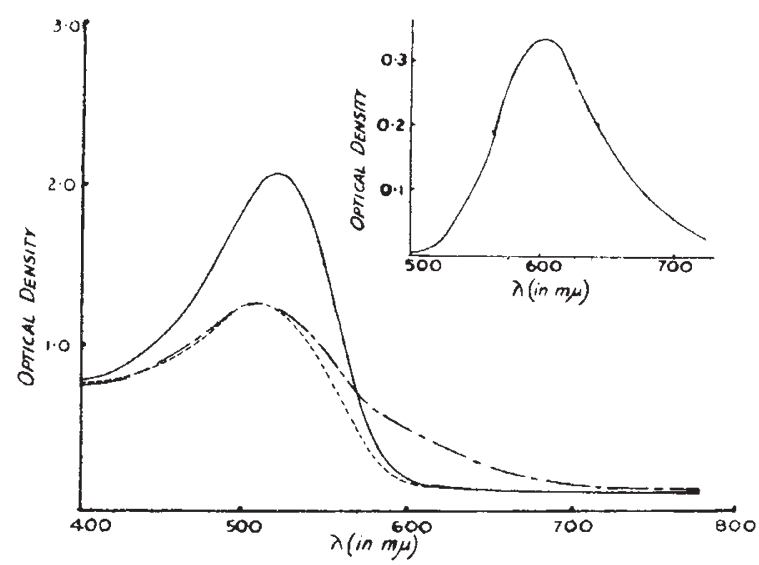

Absorption spectrum of 'Perspex Red 400'

Curve 1, - before irradiation ; curve $2,--$ immediately after irradiation; curve $3, \ldots 6$ days after curve 2 , in the presence of oxygen (complete penetration). Inset: Absorption

longer than the absorption band of the basic dye, and manifested itself visually in a darkening of the colour. At the same time the optical density in the original absorption band of the dye decreased (see diagram).

The optical density in the new band produced by a given dose of radiation increases with the concentration of the dye in the plastic, and is also dependent on the concentration of oxygen. In the absence of oxygen the change in absorption coefficient is proportional to the dose (approximately 0.02 per $\mathrm{cm}$. per 1,000 r. in 'Perspex Red 400'), whereas in the presence of dissolved oxygen in equilibrium with $1 \mathrm{~atm}$. of the gas, scarcely any change occurs for the first $10^{5}$ roentgens, and the rate of change increases at higher doses to approximately the same value as obtained in the absence of oxygen. If, after irradiation, oxygen is permitted to diffuse into the plastic, a partial reversal of the phenomenon occurs, so that the new absorption band due to the irradiation disappears; but the absorption at the original peak does not return to its normal value. A thermal backreaction is also observed, which is very slow at room temperature, taking several months for completion.

These results are interpreted as showing that some of the electrons liberated from the lattice by radiation become trapped by and attached to the dye, the proportion depending on competition for the available electrons between the dye and other acceptors in the lattice. As a result of the irradiation, a system of positive holes and negative ions is formed. The phenomenon is analogous to the production of colour centres in alkali halide crystals. The system would not normally be chemically stable, but is evidently 'frozen' into the plastic lattice, and decomposes or recombines only very slowly at room temperature. This is a noteworthy difference from, for example, aqueous solutions, where the primary processes are presumably identical, but are followed much more readily by secondary chemical reactions.

Oxygen evidently competes for the electrons, forming $\mathrm{O}_{2}^{-}$, and owing to its greater electron affinity is capable also of effecting an electron transfer from the dye :

$$
\mathrm{Dy}^{-}+\mathrm{O}_{2} \rightarrow\left(\text { dye } \ldots \mathrm{O}_{2}^{--}\right)
$$

where electron transfer has occurred, but the two species may be held together by the residual electron affinity of the dye. 